\title{
The Challenges of Research-Based Care of Patients
}

In 2013, the first issue of Faculty Seminars in Medical Principles and Practice emphasized research and its dissemination in an academic institution. This second issue emphasizes the implementation of research findings as a fundamental challenge for health-care systems to be able to optimize care, outcomes and costs. Medicine has a long tradition of both basic and clinical research. However, until recently, the process by which research results were incorporated into medical decisions was lengthy and highly subjective. With the emergence of evidence-based practice, the application of scientific methods to decisionmaking in health care is being based on the conscientious, explicit and judicious use of current best evidence. The organization of this within each medical teaching unit is challenging, but nevertheless essential. If health-care professionals are to be empowered to adopt an evidencebased approach in both the planning and delivery of care, then research awareness is crucial. The systematic review of published research studies is the main method used for evaluating particular treatments.

For the 2015 issue of Faculty Seminars, four seminars have been selected to showcase the relevance of basic and clinical research in improving patient care and the challenges involved:

P.W. Lucas and A. van Casteren [this issue, pp. 3-13] review the mechanical damage suffered by teeth crowns. The focus is on the outer enamel coat because this is the contact tissue and where most fractures start. The properties of the enamel appear to be tailored to maximize hard- ness, but also to prevent fracture. The latter is achieved by the deployment of developmental flaws called enamel tufts. Macrofractures usually appear to initiate extensions of tufts on the undersurface of the enamel adjacent to the enamel-dentine junction and extend from there into the enamel. Cracks that pass from the tooth surface tend to be deflected by an enamel region of high toughness; if they find the surface again, a chip (mesofracture) is produced. The real protection of the enamel-dentine junction here is the layer of decussating inner enamel. The local toughness of the enamel is very important in its ability to resist tissue loss.

L. Benov [this issue, pp. 14-28] discusses the present status of photodynamic therapy, a minimally invasive therapeutic modality used for the management of a variety of cancers and benign diseases. The destruction of unwanted cells and tissues in photodynamic therapy is achieved by the use of visible or near-infrared radiation to activate a light-absorbing compound (a photosensitizer), which, in the presence of molecular oxygen, leads to the production of singlet oxygen and other reactive oxygen species. These cytotoxic species damage and kill target cells. The development of new photosensitizers with properties optimized for photodynamic therapy applications is crucial for the improvement of the therapeutic outcome.

M. Oriowo [this issue, pp. 29-37] explores the role of adventitial adipose tissue, perivascular adipose tissue (PVAT), now known to secrete a number of bioactive

\begin{tabular}{|c|c|}
\hline KARGER 125/\% & $\begin{array}{l}\text { (c) 2014 S. Karger AG, Basel } \\
1011-7571 / 14 / 0241-0001 \$ 39.50 / 0\end{array}$ \\
\hline $\begin{array}{l}\text { E-Mail karger@karger.com } \\
\text { www.karger.com/mpp }\end{array}$ & $\begin{array}{l}\text { This is an Open Access article licensed under the terms of the } \\
\text { Creative Commons Attribution-NonCommercial 3.0 Un- } \\
\text { ported license (CC BY-NC) (www.karger.com/OA-license), } \\
\text { applicable to the online version of the article only. Distribu- } \\
\text { tion permitted for non-commercial purposes only. }\end{array}$ \\
\hline
\end{tabular}


substances including vascular endothelial growth factor, tumor necrosis factor- $\alpha$, leptin, adiponectin, insulin-like growth factor, interleukin-6, plasminogen activator substance, resistin and angiotensinogen. Several vasodilators have been suggested including adiponectin, angiotensins $1-7$, hydrogen sulfide and methyl palmitate. The anticontractile effect of PVAT is mediated through the activation of potassium channels since it is abrogated by inhibition of these channels. Hypertension is characterized by a reduction in the size and amount of PVAT, and this is associated with the attenuated anticontractile effect of PVAT in hypertension. Hypertension is characterized by low-grade inflammation and infiltration by macrophages, which secrete adipokines such as tumor necrosis factor- $\alpha$ and superoxides. It has been shown that exogenously administered tumor necrosis factor- $\alpha$ enhances agonist-induced contraction of vascular smooth muscle preparations and reduces endothelium-dependent relaxation. The loss could be due to an increased amount of proinflammatory and procontractile factors.

M.F.E. Diejomaoh [this issue, pp. 38-55] reviews the distressing problem of recurrent spontaneous miscarriage. Antiphospholipid syndrome has been the most recognized etiological factor; however, in $40-60 \%$ of patients, no cause is identified. Therefore, investigations include preimplantation genetic testing with the application of the recent microarray technology such as single-nucloetide polymorphism and comparative genomic hybridization as well as preimplantation genetic diagnosis. The role of low-dose aspirin, heparin, steroids and intravenous immunoglobulin in the management of idiopathic recurrent spontaneous miscarriage is not clear. Larger, randomized, double-blind, placebo-controlled studies are advocated here.

In conclusion, tooth damage is a distressing disorder that needs more research for its prevention. The development of photosensitizers for photodynamic therapy in cancer treatment is also needed. A better understanding of the role of PVAT in hypertension could lead to innovative therapeutic developments that could result in better treatment of hypertension. More knowledge from research on the etiology of recurrent spontaneous miscarriage and improving targeted treatment strategies will result in better outcomes. There is a deliberate need to prepare scientists to turn research into improved care for patients. Developing research-based clinical practice is a challenging goal. Practice based on rigorously acquired knowledge through research is preferred to tradition, trial and error. The use of a systematic approach for this process will facilitate the training and career development of clinicians and better outcomes in their clinical practice. Prof. Alexander E. Omu Guest Editor

\section{Disclosure Statement}

The author has no conflicts of interest to disclose. 